\title{
Methyloradius Palustris Gen. Nov., Sp. Nov., a Methanol-oxidizing Bacterium Isolated From Snow
}

\author{
Takeshi Miyadera \\ Hokkaido University \\ Hisaya Kojima ( $\nabla$ kojimah@lowtem.hokudai.ac.jp ) \\ Hokkaido University https://orcid.org/0000-0003-3750-8353 \\ Manabu Fukui \\ Hokkaido University
}

\section{Research Article}

Keywords: Methyloradius Palustris, Methanol-oxidizing, genomic, phenotypic

Posted Date: July 9th, 2021

DOI: https://doi.org/10.21203/rs.3.rs-687530/v1

License: (c) (i) This work is licensed under a Creative Commons Attribution 4.0 International License.

Read Full License 


\section{Methyloradius palustris gen. nov., sp. nov., a methanol-oxidizing}

\section{2 bacterium isolated from snow}

6 1. Graduate School of Environmental Science, Hokkaido University, Kita-10, Nishi-5, 7 Kita-ku, Sapporo, 060-0810, Japan

8 2. The Institute of Low Temperature Science, Hokkaido University. Kita-19, Nishi-8, 9 Kita-ku, Sapporo 060-0819, Japan

$11 *$ Corresponding author

12 Tel/fax number: +81 117065460

13 E-mail: kojimah@lowtem.hokudai.ac.jp

14 The Institute of Low Temperature Science, Hokkaido University. Kita-19, Nishi-8, Kita15 ku, Sapporo 060-0819, Japan 


\section{Abstract}

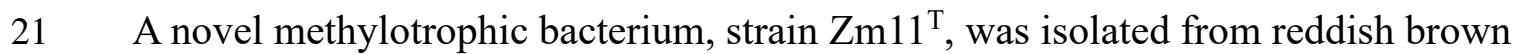
snow collected in a moor in Japan. Cells of the isolate were Gram-stain-negative, motile and rod-shaped $(0.6-0.7 \times 1.2-2.7 \mu \mathrm{m})$. Growth was observed at $5-32^{\circ} \mathrm{C}$ with an optimum growth temperature of $25-28^{\circ} \mathrm{C}$. The $\mathrm{pH}$ range for growth was $5.4-7.8$ with an optimum $\mathrm{pH}$ of 6.8 . The strain utilized only methanol as carbon and energy sources for aerobic growth. The major cellular fatty acids ( $>40 \%$ of total) were summed feature 3 $\left(\mathrm{C}_{16: 1} \omega 7 c\right.$ and/or $\left.\mathrm{C}_{16: 1} \omega 6 c\right)$ and $\mathrm{C}_{16: 0}$. The predominant quinone was $\mathrm{Q}-8$. The complete genome of strain $\mathrm{Zm} 11^{\mathrm{T}}$ is composed of a circular chromosome $(2,800,413 \mathrm{bp})$, with $\mathrm{G}+\mathrm{C}$ content of $46.4 \mathrm{~mol} \%$. Phylogenetic analyses were conducted based on the $16 \mathrm{~S}$ rRNA gene sequence and conserved proteins encoded in the genome. The results of analyses indicate that strain $\mathrm{Zm} 11^{\mathrm{T}}$ is a member of the family Methylophilaceae but does not belong to any existing genus. On the basis of its genomic and phenotypic properties, strain $\mathrm{Zm} 11^{\mathrm{T}}\left(=\mathrm{DSM} 111909^{\mathrm{T}}=\mathrm{NBRC} 14766^{\mathrm{T}}\right)$ is proposed as the type 
$38 \quad$ Funding

40 Fukui.

41

42 Conflicts of interest

Availability of data and material AP024110.

51 Code availability 


\section{Introduction}

Methylotrophic bacteria can grow on organic single-carbon (C1) compounds (e.g., methane, methanol and methylated compounds without $\mathrm{C}-\mathrm{C}$ bond) as sole sources of energy and carbon. They oxidize methanol to formaldehyde by methanol dehydrogenases (MDHs), which can be classified into two types: MxaFI-type and XoxF-type. The MxaFItype MDH is $\mathrm{Ca}^{2+}$-dependent heterotetrameric $\left(\alpha_{2} \beta_{2}\right)$ enzyme, consisting of two large subunits (MxaF) and two small subunits (MxaI) (Ghosh et al., 1995; Xia et al., 1992). On

61 the other hand, XoxF-type MDH is dimer of XoxF, distantly related to MxaF (sharing approximately 50\% amino acid sequence identity) (Chistoserdova, 2011). The XoxF-type MDH was identified as the first rare earth-dependent enzyme (Pol et al., 2014), and various studies have been carried out to characterize this notable enzyme (Chu \& Lidstrom, 2016; Taubert et al., 2015; Wu et al., 2015). such families, the family Methylophilaceae currently consists of six genera, Methylophillus, Methylobacillus, Methylovorus, Methylotenera, Novimethylophilus and 
methanol or methylamine aerobically. In this study, a novel methylotrophic bacterium belonging to the family Methylophilaceae was isolated and characterized.

\section{Materials and methods}

Enrichment and isolation in Ozegahara moor ( $\left.36^{\circ} 55^{\prime} 02^{\prime \prime} \mathrm{N} 139^{\circ} 11^{\prime} 26^{\prime \prime} \mathrm{W}\right)$ in Japan. To establish the first enrichment, $0.2 \mathrm{~mL}$ of melted snow was inoculated into $10 \mathrm{ml}$ of DSMZ medium 921, prepared in a serum bottle (approximately $70 \mathrm{ml}$ volume) sealed with a butyl rubber stopper. Into the head space filled with air, $20 \mathrm{ml}$ of methane was added by using a sterile syringe to make pressurized conditions. The grown culture was transferred to the same medium twice, resulting in enrichment of organisms related to methane-oxidizing bacteria and other methylotrophs. To isolate the enriched methylotroph, carbon source was changed to $1 \%(\mathrm{v} / \mathrm{v})$ methanol from methane. Finally, a pure culture of strain $\mathrm{Zm} 11^{\mathrm{T}}$ was obtained by repeated serial dilution in the same medium supplemented $0.1 \%$ yeast extract $(\mathrm{w} / \mathrm{v})$. In these procedures of enrichment and isolation, the cultures were incubated in the dark at $22^{\circ} \mathrm{C}$. The culture purity was checked by microscopy and repeated sequencing of the 16S rRNA gene fragments amplified with universal PCR primer pairs (Lane, 1991). 
91 Phenotypical characterizations

92 Cell morphology was examined by phase-contrast microscopy (Axioplan 2; Zeiss).

93 The Gram staining test was carried out using a kit (Sigma-Aldrich). Catalase activity was

94 assessed by pouring $10 \% \mathrm{H}_{2} \mathrm{O}_{2}$ solution onto a pellet of cells. Oxidase activity was carried

95 out using an oxidase test reagent (bioMérieux).

96 For chemotaxonomic analyses, strain $\mathrm{Zm} 11^{\mathrm{T}}$ was grown with DSMZ medium

97921 supplemented $1 \%(\mathrm{v} / \mathrm{v})$ methanol at $28^{\circ} \mathrm{C}$. The analyses of cellular fatty acids, polar

98 lipids and respiratory quinones were carried out by Techno Suruga Laboratory (Shizuoka,

99 Japan). The cellular fatty profile was obtained with the Sherlock Microbial Identification

100 System (MIDI) version 6.0 (database; TSBA6). Polar lipids and respiratory quinones

101 were analyzed with TLC and HPLC, respectively. Effects of temperature on growth were examined with the medium 921 supplemented with methanol, by culturing at $0,5,8,10,13,15,18,22,25,28,30,32,35$, $37^{\circ} \mathrm{C}$. The other tests for phenotypic characterization were all conducted at $22^{\circ} \mathrm{C}$. Utilization of growth substrates was tested with $\mathrm{K}$ medium, consisting of the following

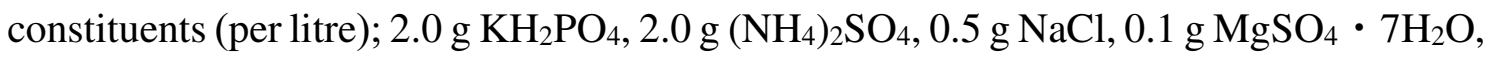


108 of the following substrates (\% w/v); glucose (0.1 and 0.5$)$, fructose $(0.1)$, sucrose $(0.1)$,

109 lactate $(0.1)$, malate $(0.1)$, succinate $(0.1)$, acetate $(0.1)$, propionate $(0.1)$, pyruvate $(0.1)$,

110 glycerol (0.1), ethanol (0.1, 0.5 and 1.0$)$, methylamine (0.1 and 0.3$)$, dimethylamine $(0.1)$

111 and yeast extract (0.1). Methane-dependent growth was tested in a closed bottle whose

112 headspace was filled with mixture of air and methane $(30 \% \mathrm{v} / \mathrm{v})$. Effect of $\mathrm{NaCl}$

113 concentration on growth was tested by altering concentration of $\mathrm{NaCl}$ in $\mathrm{K}$ medium, to 0 ,

$1140.05,0.5,1.0,2.0$ and $3.0 \%(\mathrm{w} / \mathrm{v})$. Effect of $\mathrm{pH}$ on growth was tested with modified

115 version of the $\mathrm{K}$ medium buffered with $20 \mathrm{mM}$ MES, adjusted to varying initial $\mathrm{pH}$

116 ranging from 4.6 to 8.6 (0.2-unit intervals). Nitrate reduction during aerobic growth was

117 tested by culturing in the medium 921 supplemented with $\mathrm{KNO}_{3}$ and methanol, followed

118 by chrometric detection of nitrite.

120 Genomic characterization

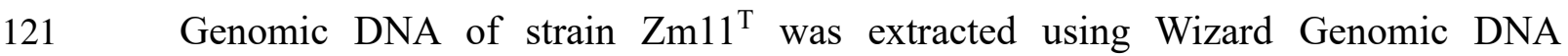

122 purification kit (Promega). Whole genome sequencing was performed using the Illumina

123 NextSeq and Nanopore GridION platforms. A hybrid assembly was performed using

124 Unicycler (Ver 0.4.7). Completeness of the assembled genome was estimated by CheckM

125 ver 1.1.2 (Parks et al., 2015). The genome sequence was annotated with DFAST 
126 (Tanizawa et al., 2018). In the annotated genome, genes encoding MDH-related proteins

127 were identified by BLASTP searches. The amino acid sequences encoded by the 128 identified genes were aligned with reference sequences of MDHs, by using the MAFFT 129 alignment tool (https://www.genome.jp/tools-bin/mafft) followed by manual inspection.

130 The alignment was imported to the program MEGA X (Kumar et al., 2018), to construct

131 a maximum likelihood tree by using the Le_Gascuel_2008 model with gamma 132 distribution (Le \& Gascuel, 2008).

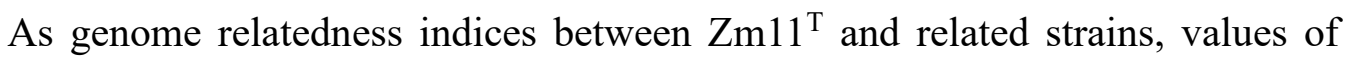
average nucleotide identity (ANI) and average amino acid identity (AAI) were calculated

135 by using tools provided by Kostas lab (http://enve-omics.ce.gatech.edu/), with the ANIb 136 algorithm (Goris et al., 2007).

138 Phylogenetic analyses

139 The 16S rRNA gene sequence of strain $\mathrm{Zm} 11^{\mathrm{T}}$ was aligned with those of type strains 140 in the family Methylophilaceae, by using CLUSTALW version 2.1(Larkin et al., 2003).

141 Based on the resulting alignment, evolutionary distances were computed by using 142 Kimura's two-parameter model with gamma distribution and invariant sites, using the 143 MEGA X. Phylogenetic trees were constructed with the maximum-likelihood, neighbor- 
144 joining and minimum evolution methods, available in the MEGA X.

145 A genome-based taxonomic classification of strain $\mathrm{Zm} 11^{\mathrm{T}}$ was conducted with the

146 Genome Taxonomy Database (GTDB), based on 120 conserved proteins (Parks et al.,

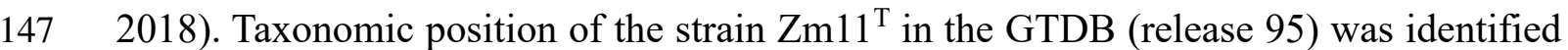

148 using GTDB-Tk (Chaumeil et al., 2020).

149

150

Accession numbers

151

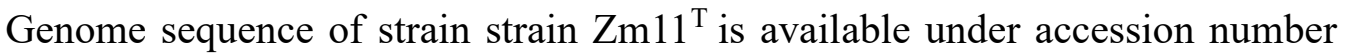

152 AP024110.

153

154

Results and Discussion

155

156

Physiological and chemotaxonomic characteristics

The fundamental characteristics of strain $\mathrm{Zm} 11^{\mathrm{T}}$ are summarized in Table 1

and species description. Cells of strain $\mathrm{Zm} 11^{\mathrm{T}}$ were motile, rod-shaped, 0.6-0.7 $\mu \mathrm{m}$ in

width, 1.2-2.7 $\mu \mathrm{m}$ in length (Fig. 1). The cells were oxidase-positive and weakly

160

positive for catalase. In the cellular fatty acid profile of the strain, summed feature 3

161

$\left(\mathrm{C}_{16: 1} \omega 7 c\right.$ and/or $\left.\mathrm{C}_{16: 1} \omega 6 c\right)$ and $\mathrm{C}_{16: 0}$ were predominant, accounting for $47 \%$ and $40 \%$ of

total, respectively. As other components, $\mathrm{C}_{10: 0} 3-\mathrm{OH}(4.3 \%), \mathrm{C}_{14: 0}(1.4 \%)$ and $\mathrm{C}_{20: 0}$ 
$163(1.2 \%)$ were detected. The other minor fatty acids detected $\left(<0.4 \%\right.$ of total) were $\mathrm{C}_{16}$ :

$164 \quad{ }_{1} \omega 5 c$ and summed feature $8\left(\mathrm{C}_{18: 1 \omega} \omega c\right.$ and/or $\left.\mathrm{C}_{18: 1} \omega 6 c\right)$. The strain had

165 phosphatidylethanolamine and phosphatidylglycerol as major polar lipids (Fig. S1).

166 Diphosphatidylglycerol and lyso-phosphatidylethanolamine were also detected along

167 with some unidentified polar lipids. In the analysis of respiratory quinone, only

168 ubiquinone 8 (Q-8) was detected.

The strain $\mathrm{Zm} 11^{\mathrm{T}}$ grew at $5-30^{\circ} \mathrm{C}$, with optimum growth at $25-30^{\circ} \mathrm{C}$. Its $\mathrm{pH}$ range for growth was 5.4-7.8, and optimum $\mathrm{pH}$ was 6.8 . The strain grew in the presence of $0.5 \%$ or lower concentrations of $\mathrm{NaCl}$, with optimal growth with $0.05 \% \mathrm{NaCl}$. No growth was observed in the presence of $1 \%$ or higher concentrations of $\mathrm{NaCl}$. $\mathrm{Zm} 11^{\mathrm{T}}$. The other substrates tested, including sugars, organic acids, amines, glycerol, methanol, nitrate reduction to nitrite was observed, as reported in related organisms (Table 1). 
reads and 44,750 GridION reads were subjected to hybrid assembly. As a result, a single

182 circular chromosome was generated with coverage of 635 -fold. The size of chromosome

183 was $2,800,413 \mathrm{bp}$, and its $\mathrm{G}+\mathrm{C}$ contents was $46.4 \%$ (Table 2). The completeness of the

184 genome was estimated to be $100 \%$.

185 In the genome of strain $\mathrm{Zm} 11^{\mathrm{T}}, 2576$ protein-coding sequences were predicted. The

186 genome harbors two copies of the 16S rRNA gene with the identical sequence. The 16S

187 rRNA gene sequence indicated the highest sequence identities to species of

188 Methylobacillus and other genera in the family Methylophilaceae, but the identities

189 were lower than $96 \%$. Phylogenetic position of strain $\mathrm{Zm}_{1} 1^{\mathrm{T}}$ in this family is shown in

190 Fig. 2. The values of ANI and AAI between the strain $\mathrm{Zm}_{1} 1^{\mathrm{T}}$ and genome-sequenced

191 strains in the family Methylophilaceae are shown in Table 2. The ANI values (76-77\%)

192 are clearly lower than $95-96 \%$, the proposed threshold for species delineation (Richter

193 \& Rosselló-Móra, 2009).

Among putative proteins encoded in the genome of strain $\mathrm{Zm} 11^{\mathrm{T}}$, those related

to MDHs were subjected to phylogenic analysis. In the genome, four genes encoding

putative MDHs were identified. As shown in Fig. S2, one of them encodes MxaF-type

$\mathrm{MDH}$ and the others encode XoxF-type MDH with distinct amino acid sequences, 

16S rRNA gene, strain $\mathrm{Zm} 11^{\mathrm{T}}$ represents sister group of a clade consisting of the genera

Methylotenera and Pseudomethylobacillus. This result was also observed in trees generated with different approaches, neighbor-joining and minimum evolution methods

206 (data not shown). The phylogenetic trees consistently indicated that strain $\mathrm{Zm} 11^{\mathrm{T}}$ is a member of the family Methylophilaceae but does not belong to any existing genera.

210 into a genus distinct from all existing genera with validly published names. The

211 genome-based phylogenetic tree is shown in Fig. S3. All these results mean that a novel

212 genus should be created to accommodate strain $\mathrm{Zm} 11^{\mathrm{T}}$.

213 The methanol-oxidizing bacterium isolated in this study, strain $\mathrm{Zm} 11^{\mathrm{T}}$, turned out to

214 be a novel member of the family Methylophilaceae. It does not belong to any existing genera in the family, as revealed by analyses of the $16 \mathrm{~S}$ rRNA gene and whole genome. 


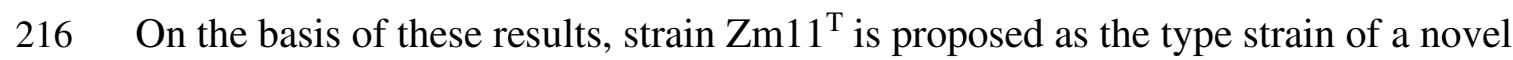

217 species of a new genus, with the name Methyloradius palustris gen. nov., sp. nov.

219 Description of Methyloradius gen. nov.

220 Methyloradius (Me.thy.lo.ra'di.us. N.L. neut. n. methylum, the methyl radical; from

221 French masc. n. méthyle; from French masc. n. méthylène; from Gr. neut. n. [ $\mu \varepsilon \dot{\theta} 0$ ] methy,

222 wine; from Gr. fem. n. [نँ $\lambda \eta]$ hylê, wood; N.L. pref. methylo-, pertaining to the methyl

223 radical; L. masc. n. radius, a staff, rod; N.L. masc. n. Methyloradius, methanol-oxidizing 224 rod).

225 Grows by oxidation of methanol as carbon and energy source. Aerobic and neutrophilic.

226 Gram-stain-negative. Major cellular fatty acids are summed feature $3\left(\mathrm{C}_{16: 1} \omega 7 \mathrm{c}\right.$ and/or

$227 \mathrm{C}_{16: 1 \omega 6 \mathrm{c})}$ and $\mathrm{C}_{16: 0}$. Belongs to the family Methylophilaceae. The type species is 228 Methyloradius palustris.

229 Description of Methyloradius palustris sp. nov.

230 Methyloradius palustris (pa.lus’tris. L.masc. adj. palustris marshy, swampy)

231 Cells are motile, rod-shaped, 0.6-0.7 $\mu \mathrm{m}$ long and 1.2-2.7 $\mu \mathrm{m}$ wide. Catalase-positive and 232 oxidase-positive. Uses oxygen as electron acceptor. Q-8 is the sole respiratory quinone. 
233 Temperature range for growth is $5-32^{\circ} \mathrm{C}$, with an optimum of $25-28^{\circ} \mathrm{C}$. Growth occurs

234 at $\mathrm{pH}$ 5.4-7.8, with an optimum of $\mathrm{pH} 6.8 . \mathrm{G}+\mathrm{C}$ content of genomic DNA of the type 235 strain is $46.4 \mathrm{~mol} \%$. Dose not grow on glucose, fructose, sucrose, lactate, malate, 236 succinate, acetate, propionate, pyruvate, glycerol, ethanol, methylamine, dimethylamine, 237 yeast extract or methane. The type strain $\mathrm{Zm}_{1} 1^{\mathrm{T}}\left(=\mathrm{DSM} 111909^{\mathrm{T}}=\mathrm{NBRC} 14766^{\mathrm{T}}\right)$ was 238 isolated from snow collected in Japan. The GenBank/EMBL/DDBJ accession numbers 239 for the complete genome sequence of strain $\mathrm{Zm}_{11} 1^{\mathrm{T}}$ is AP024110.

\section{Acknowledgments} This study was conducted as part of the 4th Oze Scientific Research, and supported by JSPS KAKENHI, Grant Number $18 \mathrm{H} 03351$ to Fukui. We thank A.

244 Shinohara for technical assistance.

\section{Reference}

247 Agafonova, N. V., Kaparullina, E.N., Doronina, N. V., Trotsenko, Y.A. (2017)

248 Methylobacillus caricis sp. nov., an obligate methylotroph isolated from roots of $249 \quad$ sedge (Carex sp.). Microbiology 86, 737-744. 
250 Chaumeil, P.-A., Mussig, A.J., Hugenholtz, P., Parks, D.H. (2020) GTDB-Tk: a toolkit to 251 classify genomes with the genome taxonomy database. Bioinformatics 36, 1925-1927.

252 Chistoserdova, L. (2011) Modularity of methylotrophy, revisited. Environ. Microbiol. 13, 253 $2603-2622$.

Chu, F., Lidstrom, M.E. (2016) XoxF acts as the predominant methanol dehydrogenase in the type I methanotroph Methylomicrobium buryatense. J. Bacteriol. 198, 13171325.

Doronina, N., Kaparrullina, E., Trotsenko, Y. (2014) The ProkaryotesStackebrandt, E., Thompson, F.(eds), 869-880.

Doronina, N. V., Trotsenko, Y.A., Kolganova, T. V., Tourova, T.P., Salkinoja-Salonen,

M.S. (2004) Methylobacillus pratensis sp. nov., a novel non-pigmented, aerobic, Microbiol. 54, 1453-1457.

Doronina, N. V., Gogleva, A.A., Trotsenko, Y.A. (2012) Methylophilus glucosoxydans sp. nov., a restricted facultative methylotroph from rice rhizosphere. Int. J. Syst. Evol. 
267 Doronina, N. V., Ivanova, E.G., Trotsenko, Y.A. (2005) Phylogenetic position and 268 emended description of the genus Methylovorus. Int. J. Syst. Evol. Microbiol. 55, $269903-906$.

Doronina, N. V., Ivanova, E.G., Trotsenko, Y.A., Pshenichnikova, A., Kalinina, E., Shvets, bacterium. Syst. Appl. Microbiol. 28, 303-309.

Doronina, N. V., Kaparullina, E.N., Trotsenko, Y.A. (2011) Methylovorus menthalis, a extorquens at 1.94 å. Structure 3, 177-187. 
flavus sp. nov. and Methylophilus luteus sp. nov., aerobic, methylotrophic bacteria associated with plants. Int. J. Syst. Evol. Microbiol. 60, 2623-2628.

Goris, J., Konstantinidis, K.T., Klappenbach, J.A., Coenye, T., Vandamme, P., Tiedje, J.M. (2007) DNA-DNA hybridization values and their relationship to whole-genome sequence similarities. Int. J. Syst. Evol. Microbiol. 57, 81-91.

Govorukhina, N., Trotsenko, Y. (1991) Methylovorus, a new genus of restricted facultatively methylotrophic bacteria. Int. J. Syst. Evol. Microbiol. 41, 158-162.

Jenkins, O., Byrom, D., Jones, D. (1987) Methylophilus: a new genus of methanolutilizing bacteria. Int. J. Syst. Evol. Microbiol. 37, 446-448.

Kalyuzhnaya, M.G., Beck, D.A.C., Vorobev, A., Smalley, N., Kunkel, D.D., Lidstrom, Methylotenera. Int. J. Syst. Evol. Microbiol. 62, 106-111. Methylotenera mobilis gen. nov., sp. nov., an obligately methylamine-utilizing bacterium within the family Methylophilaceae. Int. J. Syst. Evol. Microbiol. 56, 
301 Kaparullina, E.N., Agafonova, N. V., Trotsenko, Y.A., Doronina, N. V. (2018)

302 Methylophilus aquaticus sp. nov., a new aerobic methylotrophic bacterium isolated

303 from a freshwater reservoir. Microbiology 87, 672-80.

304 Kaparullina, E.N., Trotsenko, Y.A., Doronina, N. V. (2017) Methylobacillus methanolivorans sp. nov., a novel non-pigmented obligately methylotrophic bacterium. Int. J. Syst. Evol. Microbiol. 67, 425-431.

Kumar, S., Stecher, G., Li, M., Knyaz, C., Tamura, K. (2018) MEGA X: molecular $1547-1549$.

Lane, D.J. (1991) 16S/23S rRNA sequencing. In: Stackebrandt, E., Goodfellow, M., evolutionary genetics analysis across computing platforms. Mol. Biol. Evol. 35, H., Valentin, F., Wallace, I.M., Wilm, A., Lopez, R., Thompson, J.D., Gibson, T.J., Higgins, D.G. (2007) Clustal W and Clustal X version 2.0. Bioinformatics 23, 29472948.

Le, S.Q., Gascuel, O. (2008) An improved general amino acid replacement matrix. Mol. 
319 Lv, H., Sahin, N., Tani, A. (2018) Isolation and genomic characterization of 320 Novimethylophilus kurashikiensis gen. nov. sp. nov., a new lanthanide-dependent methylotrophic species of Methylophilaceae. Environ. Microbiol. 20, 1204-1223.

Lv, H., Sahin, N., Tani, A. (2020) Methylotenera oryzisoli sp. nov., a lanthanidedependent methylotrophic bacteria isolated from rice field soil. Int. J. Syst. Evol. Microbiol. 70, 2713-2718.

Madhaiyan, M., Poonguzhali, S., Kwon, S.-W., Sa, T.-M. (2009) Methylophilus

Madhaiyan, M., Poonguzhali, S., Senthilkumar, M., Pragatheswari, D., Lee, K.-C., Lee, rhizosphere soil. Int. J. Syst. Evol. Microbiol. 59, 2904-2908. rhizosphaerae sp. nov., a restricted facultative methylotroph isolated from rice

Parks, D.H., Chuvochina, M., Waite, D.W., Rinke, C., Skarshewski, A., Chaumeil, P.-A., Hugenholtz, P. (2018) A standardized bacterial taxonomy based on genome phylogeny substantially revises the tree of life. Nat. Biotechnol. 36, 996-1004. 
Parks, D.H., Imelfort, M., Skennerton, C.T., Hugenholtz, P., Tyson, G.W. (2015) CheckM: assessing the quality of microbial genomes recovered from isolates, single cells, and metagenomes. Genome. Res. 25, 1043-1055.

Pol, A., Barends, T.R.M., Dietl, A., Khadem, A.F., Eygensteyn, J., Jetten, M.S.M., Op den Camp, H.J.M. (2014) Rare earth metals are essential for methanotrophic life in volcanic mudpots. Environ. Microbiol. 16, 255-264.

Richter, M., Rosselló-Móra, R. (2009) Shifting the genomic gold standard for the prokaryotic species definition. Proc. Natl. Acad. Sci. 106, 19126-19131.

Sheu, C., Cai, C.-Y., Sheu, S.-Y., Li, Z.-H., Chen, W.-M. (2019) Pseudomethylobacillus aquaticus gen. nov., sp. nov., a new member of the family Methylophilaceae isolated from an artificial reservoir. Int. J. Syst. Evol. Microbiol. 69, 3551-3559.

Tanizawa, Y., Fujisawa, T., Nakamura, Y. (2018) DFAST: a flexible prokaryotic genome annotation pipeline for faster genome publication. Bioinformatics 34, 1037-1039.

Taubert, M., Grob, C., Howat, A.M., Burns, O.J., Dixon, J.L., Chen, Y., Murrell, J.C. (2015) XoxF encoding an alternative methanol dehydrogenase is widespread in coastal marine environments. Environ. Microbiol. 17, 3937-3948.

Urakami, T., Komagata, K. (1986) Emendation of Methylobacillus Yordy and Weaver 
353 Wu, M.L., Wessels, H.J.C.T., Pol, A., Op den Camp, H.J.M., Jetten, M.S.M., van Niftrik,

354 L., Keltjens, J.T. (2015) XoxF-Type methanol dehydrogenase from the anaerobic methanotroph “Candidatus Methylomirabilis oxyfera.” Appl. Environ. Microbiol. 81, $1442-1451$.

Xia, Z.X., Dai, W.W., Xiong, J.P., Hao, Z.P., Davidson, V.L., White, S., Mathews, F.S. (1992) The three-dimensional structures of methanol dehydrogenase from two methylotrophic bacteria at 2.6-A resolution. J. Biol. Chem. 267, 22289-22297. bacteria. Int. J. Syst. Bacteriol. 27, 247-255. 
Table 1. Characteristics of strain $\mathrm{Zm} 11^{\mathrm{T}}$ and those of genera in the family Methylophilaceae. ND means not determined. SF3 stands for summed feature $3\left(\mathrm{C}_{16: 1} \omega 7 c\right.$ and/or $\left.\mathrm{C}_{16: 1} \omega 6 c\right)$. Data were taken from the following references: Methylobacillus (Agafonova et al., 2017; Doronina et al., 2004; Gogleva et al., 2011; Kaparullina et al., 2017; Madhaiyan et al., 2013; Urakami \& Komagata, 1986; Yordy \& Weaver 1977), Methylophilus (Doronina et al., 2012; Doronina et al., 2005; Gogleva et al., 2010; Jenkins et al., 1987; Kaparullina et al., 2018; Madhaiyan et al., 2009), Methylotenera (Kalyuzhnaya et al., 2006; Kalyuzhnaya et al., 2012; Lv et al., 2020), Methylovorus (Doronina et al., 2005; Doronina et al., 2011; Govorukhina \& Trotsenko, 1991), Novimethylophilus (Lv et al., 2018); Pseudomethylobacillus (Sheu et al., 2019).

\begin{tabular}{|c|c|c|c|c|c|c|c|c|}
\hline & & $\mathrm{Zm} 11^{\mathrm{T}}$ & Methylobacillus & Methylophilus & Methylotenera & Methylovorus & Novimethylophilus & Pseudomethylobacillus \\
\hline \multirow[t]{2}{*}{$\begin{array}{l}\text { Temperature for } \\
\text { growth }\left({ }^{\circ} \mathrm{C}\right)\end{array}$} & Range & $5-32$ & $10-52$ & $10-37$ & $4-30$ & $10-45$ & $15-40$ & $15-30$ \\
\hline & Optimum & $25-26$ & $19-42$ & $19-37$ & $18-40$ & $24-40$ & 28 & 25 \\
\hline \multirow[t]{2}{*}{$\mathrm{pH}$ for growth } & Range & $5.4-7.8$ & $6-10.5$ & $4-10$ & $4.2-8.5$ & $4.2-8.5$ & $6-9$ & $6-8$ \\
\hline & Optimum & 6.8 & $6.5-9.5$ & $6.5-8.5$ & $5.8-7.5$ & $5.8-7.5$ & 7 & 7 \\
\hline \multirow{2}{*}{$\begin{array}{l}\mathrm{NaCl} \text { conc. for } \\
\text { growth }(\%)\end{array}$} & Range & $0-0.5$ & $0-3$ & $0-0.50$ & ND & ND & $0-2$ & $0-0.5$ \\
\hline & Optimum & 0.05 & $0.05-2.00$ & 0.05 & ND & ND & 0.05 & ND \\
\hline \multicolumn{2}{|l|}{ Nitrate reduction } & + & variable & variable & - & ND & + & + \\
\hline \multicolumn{2}{|c|}{ Major fatty acid $(>10 \%)$} & $\mathrm{C}_{16: 0}, \mathrm{SF} 3$ & $\mathrm{C}_{16: 0, \mathrm{SF} 3}$ & $\begin{array}{l}\mathrm{C}_{16: 0}, \mathrm{SF} 3, \mathrm{C}_{16: 0} 2-\mathrm{OH}, \\
\mathrm{C}_{10: 0} 3-\mathrm{OH}, \mathrm{C}_{17: 0} \text { cyclo }\end{array}$ & $\mathrm{C}_{16: 0, \mathrm{SF} 3}$ & $\begin{array}{l}\mathrm{C}_{16: 0}, \mathrm{SF} 3, \\
\mathrm{C}_{17: 0} \text { cyclo }\end{array}$ & $\mathrm{C}_{16: 0}, \mathrm{SF} 3$ & $\mathrm{C}_{16: 0}, \mathrm{SF} 3$ \\
\hline
\end{tabular}




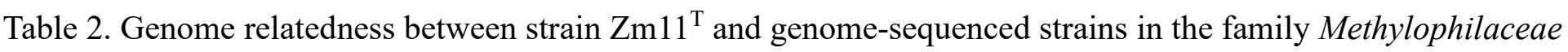

\begin{tabular}{|c|c|c|c|c|c|}
\hline Strain & Accession number & $\begin{array}{l}\text { Genome size } \\
\text { (Mbp) }\end{array}$ & $\begin{array}{l}\mathrm{G}+\mathrm{C} \text { content } \\
(\%)\end{array}$ & $\begin{array}{l}\text { ANI to } \mathrm{Zm} 11^{\mathrm{T}} \\
(\%)\end{array}$ & $\begin{array}{l}\text { AAI to } \mathrm{Zm} 11^{\mathrm{T}} \\
(\%)\end{array}$ \\
\hline $\mathrm{Zm} 11^{\mathrm{T}}$ & -- & 2.800 & 46.4 & 100 & 100 \\
\hline Methylobacillus flagellatus $\mathrm{KT}^{\mathrm{T}}$ & NC_007947 & 2.972 & 55.7 & 76.88 & 67.50 \\
\hline Methylobacillus glycogenes JCM $2850^{\mathrm{T}}$ & NZ_BAMT00000000 & 3.249 & 53.4 & 76.41 & 64.25 \\
\hline Methylobacillus rhizosphaerae Ca- $68^{\mathrm{T}}$ & NZ_FZOA00000000 & 2.368 & 52.4 & 76.77 & 67.42 \\
\hline Methylovorus glucosetrophus SIP3-4 & NC_012969 & 2.996 & 54.9 & 77.28 & 69.16 \\
\hline Methylotenera mobilis JLW8 ${ }^{\mathrm{T}}$ & NC_012968 & 2.548 & 45.5 & 76.78 & 65.50 \\
\hline Methylotenera versatilis $301^{\mathrm{T}}$ & NC_014207 & 3.060 & 42.6 & 76.25 & 65.65 \\
\hline Methylophilus methylotrophus DSM $46235^{\mathrm{T}}$ & NZ_ARJW00000000 & 2.860 & 49.6 & 76.25 & 61.45 \\
\hline Methylophilus rhizosphaerae $\mathrm{CBMB} 127^{\mathrm{T}}$ & NZ_FNFX00000000 & 2.761 & 51.4 & 76.47 & 61.48 \\
\hline Methylophilus medardicus M-51 & NZ_CP040946.1 & 2.063 & 49.8 & 77.37 & 61.36 \\
\hline Novimethylophilus kurashikiensis La2- $4^{\mathrm{T}}$ & NZ_BDOQ00000000 & 3.689 & 56.1 & 76.25 & 62.64 \\
\hline Pseudomethylobacillus aquaticus $\mathrm{H}-5^{\mathrm{T}}$ & NZ_RJVP00000000 & 2.550 & 58.3 & 77.22 & 67.57 \\
\hline
\end{tabular}


Figure legends

Fig. 1. Phase-contrast micrograph of strain $\mathrm{Zm} 11^{\mathrm{T}}$. Scale bar represents $2 \mu \mathrm{m}$.

Fig. 2. Maximum likelihood tree showing phylogenetic position of strain $\mathrm{Zm} 11^{\mathrm{T}}$ within the family Methylophilaceae, based on the 16S rRNA gene sequences. All positions containing gaps and missing data were eliminated and there were 1295 positions in the final dataset. Bar, substitutions per site. Numbers on nodes represent percentage values of 1000 bootstrap resampling. 


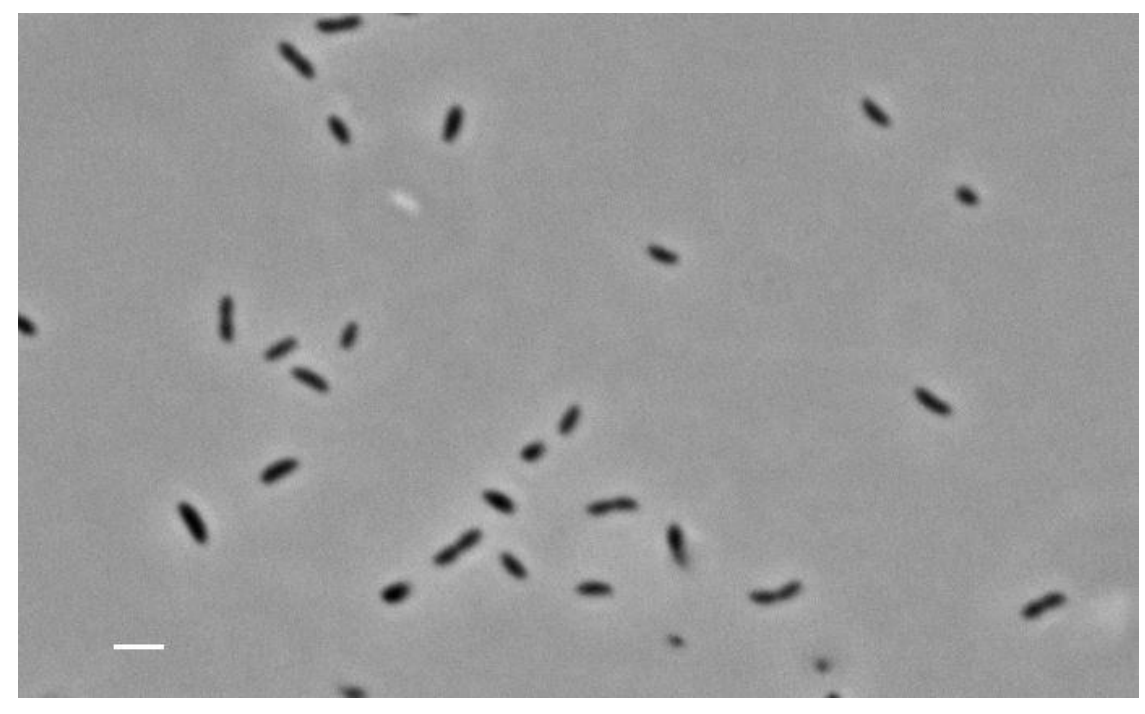




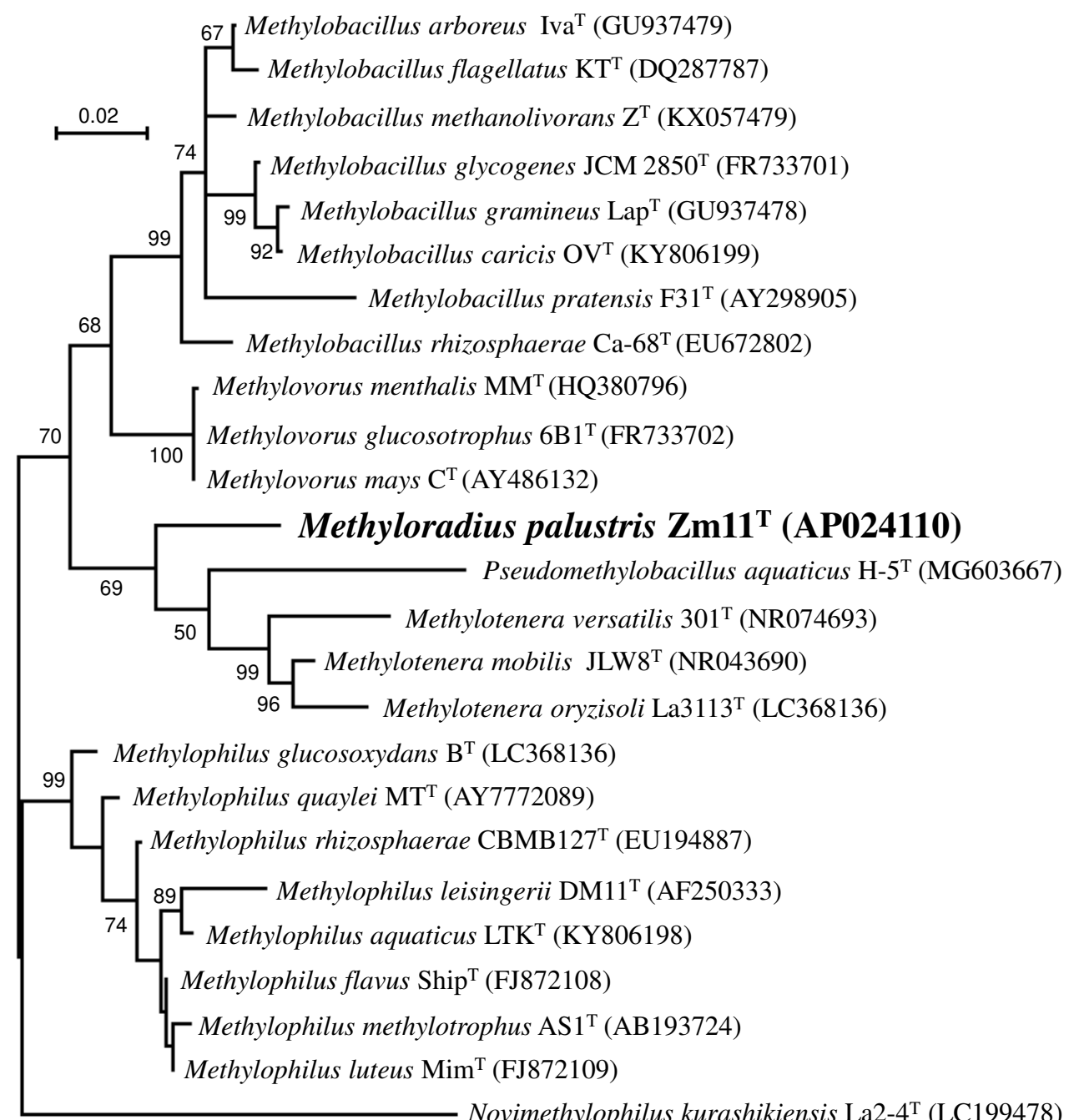

Novimethylophilus kurashikiensis La2-4 (LC199478) 


\section{Supplementary Files}

This is a list of supplementary files associated with this preprint. Click to download.

- Suppver210625.pdf 